\title{
Relationships between Personality and Burn-Out: An Empirical Study with Helping Professions' Workers
}

\author{
Paola Magnano ${ }^{1, *}$, Anna Paolillo ${ }^{2}$ and Carmine Barrano ${ }^{1}$ \\ ${ }^{1}$ Kore University, Enna, Italy \\ ${ }^{2}$ University of Verona, Italy
}

\begin{abstract}
Stress-related illnesses, such as burnout, had an increase over the last decade, even though not every employee, in the same workplace, shows burnout symptoms, suggesting that individual factors may contribute to this phenomenon. In fact, even though research on burnout generally has tended to explore the organizational factors associated with this condition, which play certainly an important role, however we cannot ignore the relationship between burnout and personality. This study explored the relationship between personality and burn-out in 144 helping professions' workers. Personality was measured by the Big Five Questionnaire; burn-out was measured by the Link Burn-out Questionnaire. Results confirm a relationship between the two constructs, partially supporting previous research that explained burn-out not only by organizational factors, but also by individual dimensions.
\end{abstract}

Keywords: Work-related stress, helping professions, Big Five model, burnout.

\section{INTRODUCTION}

The literature on the psychological cost of the cure is mostly consistent (see Maslach, Leiter and Jackson 2012). After about 35 years of studies on burnout, the studies focused their attention on two opposite domains (Schaufeli, Leiter and Maslach 2009): there are researchers who focused their attention on environment correlates that cause an exhaustion of an individual's energies or emotional resources (Pines, 1993; Hobfoll, 1989; Cordes and Dougherty 1993; Halbesleben and Buckley, 2004); other researchers, on the contrary, focused their studies on the intrinsic characteristics of workers (Piedmont, 1993; Schaufeli and Enzmann, 1998; Gustafsson, Persson, Eriksson, Norberg, and Strandberg, 2009; Alarcon, Eschleman and Bowling, 2009; Kizilci, Erdogan and Sozen, 2012).

As Alarcon, Eschelman and Bowling (2009) underlined, burnout is a negative emotional reaction to one's job that results from prolonged exposure to a stressful work environment (Maslach and Jackson, 1984); (Maslach, Schaufeli and Leiter, 2001). Burnout can be considered an indicator of low levels of employee well-being, and it is also related to employee attitudes, health, and behavior (Cordes and Dougherty, 1993; (Lee and Ashforth, 1996; (Maslach, 2003; Maslach and Goldberg, 1998; Maslach et al., 2001). Although most burnout research has focused on environmental correlates, individual factors also play an important role in the development of burnout (Maslach et al., 2001). According to Bakker, Van der Zee, Lewing

*Address correspondence to this author at the Kore University, Enna; Italy; Tel: +39 338 8887675; E-mail: paola.magnano@unikore.it and Dollard (2006) burnout is usually defined as a psychological syndrome of emotional exhaustion, depersonalization, and reduced personal accomplishment (Maslach, 1993). Emotional exhaustion refers to the depletion of psychic energy or the draining of emotional resources. Depersonalization refers to the development of negative, cynical attitudes toward the recipients of one's services. Lack of personal accomplishment is the tendency to evaluate one's own work with recipients negatively, an evaluation that is often accompanied by feelings of inefficacy (Maslach, 1993). Although more recent research has shown that burnout can be found both within and outside the human services (e.g., Bakker, Demerouti and Schaufeli, 2002), human service professionals, helping professionals' overall, are generally at relatively high risk for burnout (Schaufeli, 2003); in fact, they have very often to cope with emotionally demanding relationships with the individuals of their care. Such relationships have the aim to help others to cope with or to solve their social or health or psychological, or educational problems; often helping professionals have to deal with troubled people who suffer and are in need.

In the a recent revision of the burnout model, proposed by Santinello, Altoè, and Verzelletti (2006), a new dimension has been included, the disillusion. So the four dimensions in this revision of the burnout construct are:

1. psycho-physical exhaustion, that refers to feel tense, under pressure, without energy;

2. detriment of relationships, that describes the quality of relationship between employees and 
their clients; this relationship is characterized by insensibility, and distance form clients' problems;

3. professional inefficacy, that includes the lack of gratifications by own work;

4. disillusion, in fact burnout is considered as the arrival of a long disillusion process, in which the expectations towards the work have been totally disregarded (Edelwich and Brodsky, 1980).

Recent studies (Kizilci et al., 2012; Ghasemian, Tabatabaei and Ebrahimi, 2014) remembered that both individual and situational factors are predictor of burnout. Individual factors include demographic characteristics, personality characteristics and job attitudes. Situational factors include job characteristics, occupational characteristics and organizational characteristics (Maslach et al., 2001).

\section{BURNOUT AND PERSONALITY}

A large number of scientific research indicate that burnout is related to personality characteristics. Some researcher (Jacobs and Dodd, 2003; Rostami, Abedi and Schaufeli 2012) have found that extraversion is related with emotional exhaustion and reduced sense of personal accomplishment (Morgan and de Bruin, 2010; Zellars, Perrewe and Hochwarter, 2000), on the contrary, found that extraversion is related with depersonalization and reduced personal accomplishment.

The reasons why personality traits could be considered as moderators of burnout are: 1) in experiencing burnout, people respond to work settings in their own unique individual way (Maslach et al. 2001), so people may perceive specific aspects of a situation as more or less stressful and will react differently to situations, according to their personality characteristics (Watson, David and Suls, 1999; Vollrath, 2001; Suls and Martin, 2005); 2) personality plays a role in the stress experience, in the perception of threat and in the concomitant emotional and physiological reactions (Chung and Harding, 2009).

Other studies (Zellars et al. 2000, 2004), focusing on staff working with clients or patients without intellectual disabilities, highlighted that neuroticism is a positive predictor of emotional exhaustion and depersonalization; extraversion, agreeableness and openness negatively predicted depersonalization; and extraversion and openness positively predicted personal accomplishment. These results support the hypothesis that personality traits predict burnout components in different ways.

More recently, Gustafsson et al. (2009), have investigated the role of personality traits in a group with burnout syndrome, compared with a control-group, and found that emotional stability, mental alertness, confidence and power, are the predictor/precursors of burnout; Alarcon et al. (2009), in a meta-analytic study, found that many personality characteristics were consistently related to the three dimensions of burnout. Specifically, self-esteem, general self-efficacy, internal locus of control, emotional stability, extraversion, conscientiousness, agreeableness, positive affectivity, negatively affectivity, optimism, proactive personality, and hardiness were each related to emotional exhaustion, depersonalization, and personal accomplishment.

\section{THE BIG FIVE MODEL}

Much of the recent research on personality has been based on the Five Factors-Model, which organizes personality traits under five broad dimension: emotional stability, extraversion conscientiousness, agreeableness and openness (Costa and McCrae, 1992). Caprara, Barbaranelli, Borgogni and Perugini, (1993), and Caprara, Barbaranelli and Guido, (2001) identified a general structure composed of only five broad personality dimensions/traits, so-called "Big Five Factors". They are: 1) Energy/Extroversion, the preference for social interaction and for activity; 2) Agreeableness, the orientation toward compassion and caring about others, away from antagonism; 3) Conscientiousness, the preference for goal-oriented activity; 4) Emotional Stability, the ability to cope effectively with negative emotions; and 5) Openness, the tolerance for new ideas and new ways of doing things, experientially oriented. The five domain are composed by two subdomain each, giving a description of the personality by ten facets: energy (dynamism and dominance facets), friendliness (cooperativeness and politeness facets), conscientiousness (scrupulousness and perseverance facets), emotional stability (emotion control and impulse control facets), and openness (openness to culture and openness to experiences facets) (Caprara, Barbaranelli and Bermudez, 2000).

\section{ENERGY OR EXTROVERSION}

Energy is referred to Extroversion (McCrae and Costa, 1987) or Surgency (Goldberg, 1990), the ability to cope problems positively as well as a high frequency 
to establish social relationship (Caprara and Cervone, 2000). This dimension includes two sub-dimension, dynamism and dominance. Dynamism is referred to the energetic and dynamic behavior; this factor is decisive, ultimately, for implementation of coping strategies. Dominance refers to the ability to impose oneself, to assert the influence on other.

A large amount of research has shown the negative relationship between energy and burnout (GonzalezRoma', Schaufeli, Bakker and Lloret, 2006; see also Sonnenschein, Sorbi, van Doornen, Schaufeli and Maas, 2007); however the results about the direction of this relationship are not definitive: while the research conducted by Gustafsson et al. (2009) found that the energy or extraversion is a stable predictor of burnout, Francis, Louden and Rutledge (2004) and Zellars et al. (2000), found a negative association between extroversion and depersonalization; Eastburg, Williamson, Gorsuch and Ridley (1994), and Francis et al. (2004), have consistently found a positive association between extroversion and personal accomplishment.

On the basis of this consideration we expect, as follows:

Hypothesis 1: energy will negatively predict burn-out in all of its dimensions, e.g. psycho-physical exhaustion, detriment of relationships, professional ineffectiveness and disillusion.

\section{Agreeableness or Friendliness}

It is characterized by good-naturalness, cooperativeness, and trust. While this factor is more commonly called agreeableness, it can also be seen as a combination of friendliness and compliance. Persons who show high scores on this dimension tend to describe themselves as very cooperative, friendly, altruist, generous and empathic. This dimension is defined by two sub-dimension, respectively, cooperativeness and politeness: the first is related to the ability to cooperate effectively with other, the second measures aspects of affability, trust and openness towards others. Piedmont (1993) showed that agreeableness is negatively related with emotional exhaustion and positively with personal accomplishment. Zellars et al. (2000) highlighted that higher levels of agreeableness appear to reduce the tendency to depersonalization. Bakker et al. (2006) found a negative relationship between agreeableness and emotional exhaustion and depersonalization, positive relationship with the personal accomplishment. More recently, confirming Bakker et al.'s study, Alarcon et al. (2009), found a negative relationship between agreeableness and emotional exhaustion. On the basis of this consideration we expect, as follows:

Hypothesis 2: agreeableness will
negatively predict burn-out in all of its
dimensions, e.g. psycho-physical
exhaustion, detriment of relationships,
$\begin{aligned} & \text { professional ineffectiveness and } \\ & \text { disillusion. }\end{aligned}$

\section{Conscientiousness}

It is characterized by orderliness, responsibility, and reliability; this factor is sometimes associated with problem solving and efficacy in coping (Watson and Hubbard, 1996). People who get high score in this dimension tend to describe themselves as very thoughtful, meticulous, tide, accurate and very persevering. This dimension is composed by two subdimension, respectively, scrupulousness and perseverance: the first concerns the caution, reflexivity, orderliness, and attention to details, while the second concerns aspect that relate to the persistence and tenacity in achieving the goals and completing undertaken activities. The literature about the influence of this dimension in burn-out is not definitive: as reported by Bakker et al. (2006), Piedmont (1993), Deary, Blenkin, Agius, Endler, Zealley and Wood (1996), and Deary, Watson and Hogston (2003), there is a positive relationship between conscientiousness and personal accomplishment. Deary et al. (2003), in a longitudinal analysis of burnout in nursing students, indicated a positive relationship between conscientiousness and depersonalization. Then, LePine, LePine and Jackson (2004) found a negative association between conscientiousness and emotional exhaustion. We expect, as follows:

Hypothesis 3: consciousness will
negatively predict burn-out in all of its
dimensions, e.g. psycho-physical
exhaustion, detriment of relationships,
professional ineffectiveness and
disillusion.

\section{Emotional Stability}

It is referred to the ability to cope effectively with negative emotions. People that are emotionally stable 
are able to tolerate the day to day strains and stresses, are able to manage effectively their emotions, without anxiety or anger. Emotional instability is considered close to neuroticism and is described as a tendency to experience negative, distressing emotions and to possess associated behavioral and cognitive traits; the traits that characterize this dimension are fearfulness, irritability, low self-esteem, social anxiety, poor inhibition of impulses, and helplessness (Costa and McCrae, 1987).

This dimension is characterized by two cluster of traits: emotion control and impulse control. Emotion control includes the control of the states of tension related to emotional experience; impulse control is related to the ability to keep control of the own behavior, even in difficulty situation, conflict and danger.

As reported by Bakker et al. (2006), many studies (e.g., Deary et al., 1996; Hills and Norvell, 1991; LePine et al., 2004; Lingard, 2003; Zellars et al., 2000) on the relationship between emotional instability and burnout have typically shown that individuals who are high in emotional instability are more likely to report feelings of emotional exhaustion, to report lower levels of personal achievement, and - if health care providers - to dehumanize their patients (depersonalization). In a study of intensive-care nursing staff, Buhler and Land (2003) found that individuals who were higher in neuroticism experienced higher levels of emotional exhaustion and depersonalization.

In our study, we expect, as follows:

Hypothesis 4: emotional stability will negatively predict burn-out in all of its dimensions, e.g. psycho-physical exhaus- tion, detriment of relationships, professsional ineffectiveness and disillusion.

\section{Openness}

It refers to originality, curiosity, and ingenuity; this factor is sometimes referred to intellectualism and independence of mind. This dimension is defined by two sub-dimension: openness to culture and openness to experience. The first tends to include the interest to be informed, and to acquire knowledge. The second is referred to the favorable disposition toward innovation, to the ability to consider everything from multiple perspectives, openness to different ways of life and different cultures. In addition, openness to experience has been related to the use of humor as a way of dealing with stress (McCrae and Costa, 1987). Smith and Williams (1992) posited that this factor may be associated with stress reduction because situations are appraised as less threatening by individuals who score high on this factor.

Bakker et al. (2006) found that the relationship between openness and burnout is generally weak, such as Deary et al. (1996), which found a modest but significant positive relationship between openness and personal accomplishment. Zellars et al. (2000) also reported a positive relationship between openness and personal accomplishment and, in addition, found a negative relationship between openness and depersonalization. Other research (Morgan and de Bruin, 2010) found a positive relationship between openness and professional efficacy.

So, we expect, as follows, that:

Hypothesis 5: openness will negatively predict burn-out in all of its dimensions,

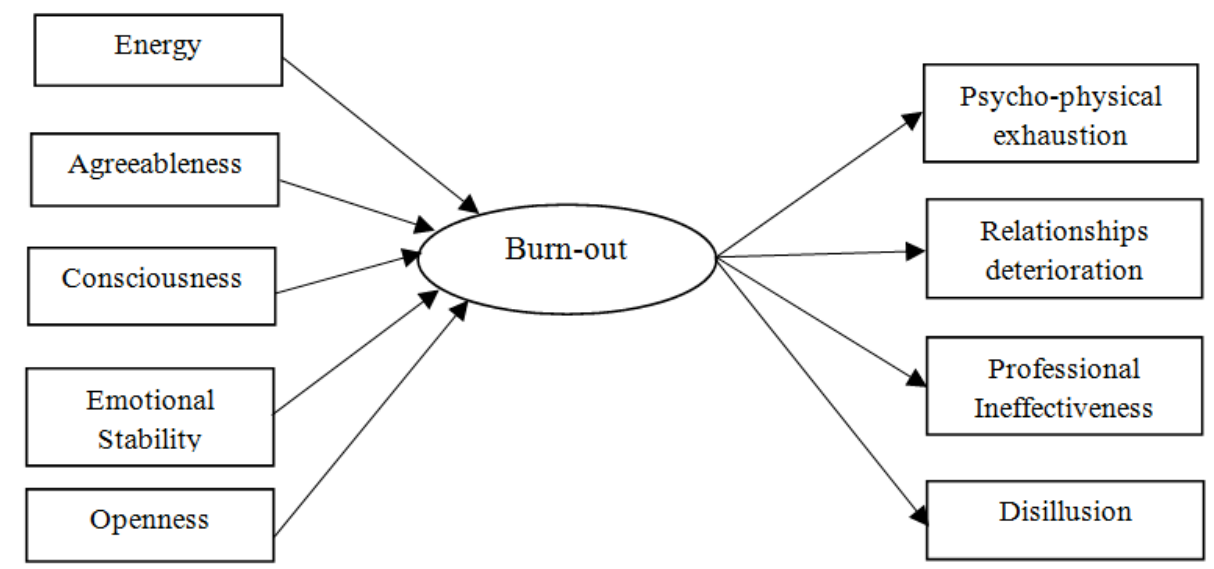

Figure 1: 
e.g. psycho-physical exhaustion, detriment of relationships, professional ineffectiveness and disillusion.

The theoretical model is presented in Figure 1.

\section{MATHERIALS AND METHOD}

\section{Design and Procedure}

The participation to this cross-sectional study was completely voluntary. The participants have been recruited on a voluntary basis; tests have been administrated individually, anonymously, and without time limits. The survey was reviewed and approved by the Ethics Commission of Kore University and the University of Verona. The research protocol included the two surveys presented in the following paragraph; the order of the surveys was counterbalanced.

\section{Measures}

The Big Five Questionnaire 2 (BFQ-2) (Caprara, Barbaranelli, Borgogni and Vecchione, 2007) is a 134 items self-response scale which reveals 5 big factors that describe personality; each factor is divided into two sub-domains:

1. E: Energy refers to the factor usually labeled as Extraversion or Surgency, is composed by Dynamism (Dy; sample item: I feel active and vigorous) and Dominance (Do; sample item: Usually I tend to impose myself rather than acquiesce). Cronbach's $\alpha=0.85$.

2. A: Agreeableness refers to the factor usually labeled as Friendly Compliance vs. Hostility. The sub-dimensions are Cooperation ( $\mathrm{Cp}$; sample item: I always know how to meet other people's needs) - Friendliness (Fr; sample item: People should show always polite with everyone) Cronbach's $\alpha=0.87$.

3. C: Conscientiousness refers to self-regulation in both its proactive and inhibitory aspects. It includes Scrupulosity (Sc; sample item: I usually take care of everything in the smallest detail) Perseverance (Pe; sample item: I carry out the decisions I have taken). Cronbach's $\alpha=0.85$.

4. S: Emotional Stability refers to characteristics of personality defined as the capacity to cope adequately with one's own anxiety and emotionality and the capability of controlling irritation, discontent and anger. The sub-domains are Emotion control (Ec; sample item: I do not feel an anxious person) and Impulse control (Ic; sample item: I do not usually react in an impulsive way). Cronbach's $\alpha=0.90$

5. O: Openness refers to the factor labeled as Culture or Intellect or Openness to Experience. It includes Openness to culture (Oc; sample item: Reading is one of my favorite activities) and Openness to experience (Oe; sample item: Every new thing fascinates me). Cronbach's a $=0.88$.

Each facet scale contains 12 items, half of which are positively phrased with respect to the scale name and half negatively phrased, to control for a possible acquiescent response set. In addition, there is a lie (L) scale designed to measure a social desirability response set and the tendency to distort meanings of the scores. The $\mathrm{L}$ scale contains 14 items that are all positively phrased. For each of the 134 items in the questionnaire, there is a 5-point answer scale that ranges from complete disagreement ( $1=$ very false for me) to complete agreement ( $5=$ very true for me).

The Link Burnout Questionnaire (LBQ) (Santinello, Altoè and Verzelletti, 2006) is composed by 24 item grouped in four dimensions (8 items for each dimension, 4 positive and 4 negative), as described above in the article:

Psycho-physical exhaustion, sample item: I feel physically exhausted from my work. Cronbach's $\alpha=0.81$

Detriment of the relationships, sample item: My patients seem thankless. Cronbach's $\alpha=0.77$

Professional Inefficacy, sample item: I feel inadequate to face the problems of my patients. Cronbach's $\alpha=0.83$

Disillusion, sample item: I doubt that what I do has any value. Cronbach's $\alpha=0.86$

\section{Participants}

Participants were 144 Italian helping-profession workers (32 males, 112 females), aged between 20 and 63 years $(M=39.56 ; S D=9.61)$. They were educators in communities for disadvantaged children and adolescents, working in Italian context. The prevalence of women workers over men workers can 
be derived from the limited diversity characterizing the company sector from which the participants come: specifically they represent highly feminized professions $(63.4 \%$ of individuals employed in the health and family services are women; Italian National Institute of Statistics, [ISTAT], 2013).

\section{Data Analysis}

The actual survey data were analysed with structural equation modelling (SEM). Tests were completed in AMOS 22.0 (Arbuckle and Wothke, 1999) applying the maximum-likelihood (ML) method. Firstly a confirmatory factor analysis (CFA) was used to test the factor structure of the measures (Byrne, 2001). According to Harris and Schaubroeck (1990), CFA is most appropriate to use with established measures. Following Hair, Black, Babin, Anderson and Tatham (2006), multiple fit indices were used to assess the model's goodness-of-fit. The comparative fit index (CFI), the Goodness of Fit Index (GFI), the Standardized Root Mean Square Residual (SRMR) and the root-mean-square error of approximation (RMSEA) were used to test the model fit of the measurement model. After the measurement model was verified, this study performed the analysis of structural model to confirm the hypothesized relationships.

Other well-known analytical tools such as correlations were also used, which were implemented by using SPSS 21.0 .

\section{RESULTS}

\section{Descriptives and Correlations}

Table 1 provides an overview of the means, standard deviations and correlations between the variables.

\section{CFA of the Measures}

The fit statistics revealed that the tested model fits the data adequately: $X^{2}(64)=121.360 ; p<.001 ; \mathrm{GFI}=$ $.90 ; \mathrm{CFI}=.89$; SRMR = .06; RMSEA $=.079$, indicating a good model fit. All variables were measured from the same source (helping professions' workers), and therefore common method bias (Podsakoff, MacKenzie, Lee and Podsakoff, 2003) may occur.

To address potential CMV, Harman's single-factor test was adopted. A comparison between the hypothesized model (the five personality traits and burn-out as separate factors) and a one-factor model (with all items loading on a single factor) revealed that the hypothesized model provided better fit for the data $\left(\Delta X^{2}(14)=362.821\right)$. According to these results, no evidence for common method bias was found in the data.

\section{Structural Model}

After the above CFA model was verified, the analysis of structural model was performed. The results reveal that only some of the theoretical hypotheses were empirically supported.

Results showed that:

Energy did not significantly predict any burn-out factor, therefore hypothesis 1 was not supported;

Agreeableness did not significantly predict any burn-out factor, therefore hypothesis 2 was not supported;

Consciousness did not significantly predict any burn-out factor, therefore hypothesis 3 was not supported;

Table 1: Means, Standard Deviations and Correlations among Study Variables

\begin{tabular}{|c|c|c|c|c|c|c|c|c|c|c|c|}
\hline Variables & M & SD & 1 & 2 & 3 & 4 & 5 & 6 & 7 & 8 & 9 \\
\hline 1. Energy & 77,56 & 8,54 & 1 & & & & & & & & \\
\hline 2. Agreeableness & 92,64 & 8,37 & $.24^{* *}$ & 1 & & & & & & & \\
\hline 3. Consciousness & 88,68 & 8,08 & $.23^{* *}$ & $.35^{* *}$ & 1 & & & & & & \\
\hline 4. Emotional Stability & 76,75 & 11,94 & .03 & .14 & .12 & 1 & & & & & \\
\hline 5. Openness & 85,09 & 12,39 & $.36^{* *}$ & $.33^{* *}$ & $.34^{* *}$ & $.29^{* *}$ & 1 & & & & \\
\hline 6. Exhaustion & 12,52 & 4,49 & -.03 & -.03 & -.15 & $-.26 *$ & -.09 & 1 & & & \\
\hline 7. Deterioration & 12,57 & 4,40 & .02 & -.12 & -.13 &,$- 21^{*}$ & $-.28 *$ & $.41^{* *}$ & 1 & & \\
\hline 8. Ineffectiveness & 11,55 & 4,22 & -.11 & -.15 & $-.20^{*}$ & $-.33^{* *}$ & $-.21^{*}$ & $.37^{* *}$ & $.27^{* *}$ & 1 & \\
\hline 9. Disillusion & 11,52 & 5,23 & .08 & -.06 & $-.17^{*}$ & $-.23^{* *}$ & -.11 & $.50^{* *}$ & $.47^{* *}$ & $.43^{* *}$ & 1 \\
\hline
\end{tabular}

${ }^{* *} p<.001 ;{ }^{*} p<.01$. 
Emotional stability negatively predicted exhaustion $(\beta=-.25, p<.01)$, professional inefficacy $(\beta=-.33, p<.01)$ and disillusion $(\beta=-$ $.23, p<.01)$, thus partially confirming hypothesis 4

Openness negatively predicted detriment of the relationships $(\beta=-.27, p<.001$ ), thus partially confirming hypothesis 5 .

\section{DISCUSSION}

The aim of the study was to verify the relationship between burn-out and personality; we hypothesized that helping professions' workers, in particular community educators, which had higher levels of personality resources could show lower levels of burnout symptoms. Data analysis partially supported the hypothesis, showing the following results: energy, agreeableness and consciousness were found to be not significantly related to any burn-out factor; emotional stability was negatively related to psychophysical exhaustion, professional inefficacy and disillusion, partially confirming hypothesis 4 ; openness was negatively related to detriment of relationships, partially confirming hypothesis 5 .

Some of these results could seem unexpected, however the literature about personality and burn-out is not definitive. For example, Alarcon et al. (2009), in their meta-analytic review, conclude that "although our hypotheses simply predicted that each personality trait would be related to each of the three burnout dimensions, we should note that some personality traits yielded stronger relationships with burnout than did others" (p. 257).

The lack of relationships between energy and consciousness on the one hand and burn-out, on the other, maybe is explainable because these two personality characteristics can be considered as nonaffective-oriented variables (Thoresen et al., 2003), while dimensions of burn-out are affective-oriented variables. This explanation is based on the assumption that affective-oriented variables will show stronger relationships with other affective-oriented variables than with non-affective variables (Weiss, 1996). Similar reasoning may also explain why emotional stability had significant relationships with three of the four dimensions of burn-out.

Concerning the absence of relationship between burn-out and agreeableness, in the literature review have been found contradictory results: Deary et al. (1996) found no relationship between agreeableness and personal accomplishment; Zellars et al. (2000) reported similar results and found a weak negative relationship between agreeableness and depersonalization, whereas no relationship was found between agreeableness and the two other burnout variables.

The openness, which in our study was found to be negatively related to detriment of relationships confirmed the results of previous studies, which reported a positive relationship between openness and personal accomplishment considered the opposite of the detriment of the relationships) and a negative relationship between openness and depersonalization (Zellars et al., 2000).

The relationship between emotional stability and burn-out is the most frequent to be found in research (Bakker et al., 2006). In our study emotional stability was found to be negatively related with emotional exhaustion, professional inefficacy and disillusion. Individuals with emotional instability tend to experience negative and distressing emotions; this factor is characterized by fearfulness, irritability, low selfesteem, social anxiety, poor inhibition of impulses, and helplessness (Costa and McCrae, 1987). As Bakker et al. (2006) highlighted, previous studies (e.g., Deary et al., 1996; Hills and Norvell, 1991; LePine et al., 2004; Lingard, 2003; Zellars et al., 2000) on the relationship between neuroticism (that is the opposite of emotional stability) and burnout have shown that individuals who show high levels of neuroticism are more likely to report feelings of emotional exhaustion, lower levels of personal achievement, and - specifically for helping professions' workers - they tend to dehumanize their patients (depersonalization). In a study about the relationship between burnout and personality variables in intensive-care nursing staff, Buhler and Land (2003) found that individuals who were higher in neuroticism experienced higher levels of emotional exhaustion and depersonalization. Also Cano-García, Padilla-Muñoz and Carrasco-Ortiz (2005) confirmed the hypothesis that the highest scores in burnout (greater emotional exhaustion, greater depersonalization and less personal accomplishment) were obtained with a high degree of neuroticism and introversion, in a sample of teachers.

At last, maybe helping professions' is not an unique and homogeneous professional category: it includes health care, social service work, teaching, and other 
"caring" professions that have different emotional involvement with people. Researchers have demonstrated differences in dimensions of burnout for different service and caring professions (Singh et al., 1994) and have developed taxonomies of "highburnout" jobs based on their frequency of interactions (Cordes and Dougherty, 1993) and the emotion control needed while interacting with the public. In a study of Brotheridge and Grandey (2002) were found significant differences in the nature of prototypical emotional labor occupations (service/sales) and burnout occupations (caring work). The results suggested the existence of a hierarchy of emotional labor expectations, with human service professionals reporting the highest levels of frequency, variety, intensity, and duration of emotional display and expectations for control over emotional expressions. Our participants could be considered as "high-touch workers", because they often share many time with the persons they care: in fact they have the responsibility of the education of children and adolescence with personal and social difficulties. Certainly, some personality factors - as emotional stability - affect burn-out symptoms, as highlighted in previous studies and in present research; however, some job characteristics could explain burn-out, and future studies could compare different kind of helping professions' workers.

\section{LIMITATIONS AND CONCLUSIONS}

The study presents some limitations. First of all, study variables were measured from the same source (helping professions' workers) thus creating a singlesource bias. Although statistical steps (Harman's single-factor test) provided an indication that a single factor does not account for all co-variances among the items, it would be better to control for this effect at the research design stage, i.e. future research should collect the ratings at different times and from separate sources.

A second limitation of the study is the crosssectional measurement. It was not possible to test the causal relationships proposed in the theoretical framework. Despite this consideration, the use of structural equation analyses enabled us to demonstrate a series of hypotheses that were consistent with a causal theory

A further limitation of the study was the use of convenience sampling methods for data collection. While cross-sectional convenience samples may prove useful in exploring theoretical models, such as the one built in the present study, caution should be exercised while generalizing the results beyond the current research. However, though this study supports existing research on the relationship between the big five personality traits and burnout, the use of Link Burn-out Questionnaire, which introduces a new dimension, the disillusion, in addiction to the traditional Maslach's three aspects (emotional exhaustion, depersonalization, professional inefficacy), can be considered as an original novelty and a strenght of the study. Moreover, the results suggest future research indications, exploring the differences among different kind of helping professions' workers.

\section{REFERENCES}

Alarcon, Gene, Kevin J. Eschleman and Nathan A. Bowling. 2009. "Relationships between Personality Variables and Burnout: A Meta-Analysis." Work \& Stress 23(3):244-63. http://dx.doi.org/10.1080/02678370903282600

Arbuckle, James L. and Werner Wothke. 1999. Amos 4.0. Chicago, IL: Smallwaters.

Bakker, Arnold B., Evangelia Demerouti and Wilmar B. Schaufeli. 2002. "Validation of the Maslach burnout inventory-general survey: An internet study." Anxiety, Stress \& Coping 15.3: 245-260. http://dx.doi.org/10.1080/1061580021000020716

Bakker, Arnold B., Karen I. Van der Zee, Kerry A. Lewig and Maureen F. Dollard. 2006. "The Relationship between the Big Five Personality Factors and Burnout: A Study among Volunteer Counselors." The Journal of Social Psychology 146(1):31-50 http://dx.doi.org/10.3200/SOCP.146.1.31-50

Brotheridge, Céleste M. and Alicia A. Grandey. 2002. "Emotional Labor and Burnout: Comparing Two Perspectives of "People Work"." Journal of Vocational Behavior 60.1: 17-39. http://dx.doi.org/10.1006/jvbe.2001.1815

Bühler, K-E. and Tatjana Land. 2003. "Burnout and personality in intensive care: an empirical study." Hospital topics 81.4: 512.

http://dx.doi.org/10.1080/00185860309598028

Byrne, Barbara M. 2001. Structured equation modeling with AMOS: Basic concepts, applications, and programming. Mahwah, NJ: Lawrence Erlbaum Associates.

Cano-García, Francisco Javier, Eva Maria Padilla-Muñoz and Migue Ángel Carrasco-Ortiz. 2005. "Personality and contextual variables in teacher burnout." Personality and Individual differences 38.4: 929-940.

http://dx.doi.org/10.1016/j.paid.2004.06.018

Caprara, Gian Vittorio, and Daniel Cervone. 2000. Personality: Determinants, Dynamics, and Potentials. Cambridge: Cambridge University Press. http://dx.doi.org/10.1017/CBO9780511812767

Caprara, Gian Vittorio, Claudio Barbaranelli and Gianluigi Guido. 2001. "Brand Personality: How to Make the Metaphor Fit?" Journal of Economic Psychology 22:377-95. http://dx.doi.org/10.1016/S0167-4870(01)00039-3

Caprara, Gian Vittorio, Claudio Barbaranelli, Jose Bermudez, Christina Maslach and Willibald Ruch. 2000. "Multivariate Methods for the Comparison of Factor Structures in CrossCultural Research: An Illustration with the Big Five Questionnaire." Journal of Cross-Cultural Psychology 31(4):437-64 http://dx.doi.org/10.1177/0022022100031004002 
Caprara, Gian Vittorio, Claudio Barbaranelli, Laura Borgogni and Marco Perugini. 1993. "The 'big Five Questionnaire': A New Questionnaire to Assess the Five Factor Model." Personality and Individual Differences 15(3):281-88.

http://dx.doi.org/10.1016/0191-8869(93)90218-R

Caprara, Gian Vittorio, Claudio Barbaranelli, Laura Borgogni and Michele Vecchione. 2007. BFQ-2: Manuale. Firenze, Italy: OS.

Chung, Man Cheung and Carly Harding. 2009. "Investigating Burnout and Psychological Well-Being of Staff Working with People with Intellectual Disabilities and Challenging Behaviour: The Role of Personality." Journal of Applied Research in Intellectual Disability 22(2001):549-60. http://dx.doi.org/10.1111/j.1468-3148.2009.00507.x

Cordes, Cynthia L. and Thomas W. Dougherty. 1993. "A Review and an Integration on Job Burnout." Academy of Management Review 18(4):621-56.

Costa, Paul T. and Robert R. McCrae. 1992. Revised Neo Personality Inventory (NEO-PI-R) and NEO Five-Factor Inventory (NEO-FFI). Psychological Assesment Resources.

Deary, Ian J., Harriet Blenkin, Raymond M. Agius, Norman S. Endler, Helen Zealley and Robert Wood. 1996. "Models Of JobRelated Stress And Personal Achievement Among Consultant Doctors." British Journal of Psychology 87:3-29. http://dx.doi.org/10.1111/j.2044-8295.1996.tb02574.x

Deary, lan J., Roger Watson and Richard Hogston. 2003. "A longitudinal cohort study of burnout and attrition in nursing students." Journal of Advanced Nursing 43.1:71-81. http://dx.doi.org/10.1046/j.1365-2648.2003.02674.x

Eastburg, Mark C., Mike Williamson, Richard Gorsuch and Charles Ridley. 1994. "Social support, personality, and burnout in nurses." Journal of Applied Social Psychology 24.14:12331250.

http://dx.doi.org/10.1111/j.1559-1816.1994.tb00556.x

Edelwich, Jerry and Archie Brodsky. 1980. "Burn-Out: Stages of Disillusionment in the helping professions. New York: Human Sciences Press

Francis, Leslie J., Stephen H. Louden and Christopher J. F. Rutledge. 2004. "Burnout Among Roman Catholic Parochial Clergy in England and Wales: Myth or Reality?" Review of Religious Research 46(1):5-19.

http://dx.doi.org/10.2307/3512249

Ghasemian, Daryoush, Tayyebeh Tabatabaei and Sedigheh Ebrahimi. 2014. "Relationship between Burnout and Personality Traits, a Study among Doctors and Staffs of Mazandaran Legal Medicine Organization, Iran." Journal of Social Issues \& Humanities 2(8):8-10.

Goldberg, Lewis R. 1990. "An Alternative "Description of Personality": The Big-Five Factor Structure." Journal of Personality and Social Psychology 59.6: 1216.

González-Romá, Vicente, Wilmar B. Schaufeli, Arnold B. Bakker and Susana Lloret. 2006. "Burnout and Work Engagement: Independent Factors or Opposite Poles?" Journal of Vocational Behavior 68(1):165-74. http://dx.doi.org/10.1016/j.jvb.2005.01.003

Gustafsson, Gabriella, Birgitta Persson, Sture Eriksson, Astrid Norberg and Gunilla Strandberg. 2009. "Personality Traits among Burnt out and Non-Burnt out Health-Care Personnel at the Same Workplaces: A Pilot Study." International Journal of Mental Health Nursing 18(5):336-48. http://dx.doi.org/10.1111/j.1447-0349.2009.00623.x

Hair Joseph F., William C. Black, Barry J. Babin, Rolph E. Anderson and Ronald L. Tatham. 2006. Multivariate Data Analysis (6th Ed.). Upper Saddle River, NJ: Pearson-Prentice Hall.

Halbesleben, Jonathon R. B. and M. Ronald Buckley. 2004. "Burnout in Organizational Life." Journal of Management 30:859-79. http://dx.doi.org/10.1016/j.jm.2004.06.004

Harris, Michael M. and John Schaubroeck. 1990. "Confirmatory modeling in organizational behavior/human resource management: Issues and applications." Journal of Management 16.2:337-360.

http://dx.doi.org/10.1177/014920639001600206

Hills, Holly and Nancy Norvell. "An examination of hardiness and neuroticism as potential moderators of stress outcomes." Behavioral Medicine 17.1 (1991): 31-38. http://dx.doi.org/10.1080/08964289.1991.9937550

Hobfoll, Stevan E. 1989. "Conservation of Resources. A New Attempt at Conceptualizing Stress." The American psychologist 44(3):513-24. http://dx.doi.org/10.1037/0003-066X.44.3.513

ISTAT. 2013. Rapporto Annuale 2013. La Situazione del Paese. Roma: ISTAT.

Jacobs, Sheri R. and David Dodd. 2003. "Student burnout as a function of personality, social support, and workload." Journal of College Student Development 44.3:291-303. http://dx.doi.org/10.1353/csd.2003.0028

Kizilci, Sevgi, Vesile Erdogan and Emin Sozen. 2012. "The Influence of Selected Personality and Workplace Features on Burnout among Nurse Academics." The Turkish online Journal of Educational Technology 11(4):307-15.

Lee, Raymond T. and Blake E. Ashforth. 1996. "A Meta-Analytic Examination of the Correlates of the Three Dimensions of Job Burnout." Journal of Applied Psychology 81(2):123-33. http://dx.doi.org/10.1037/0021-9010.81.2.123

LePine, Jeffrey A., Marcie A. LePine and Christine L. Jackson. 2004. "Challenge and hindrance stress: relationships with exhaustion, motivation to learn, and learning performance." Journal of Applied Psychology 89.5:883.

Lingard, Helen. 2003. "The impact of individual and job characteristics on 'burnout' among civil engineers in Australia and the implications for employee turnover." Construction Management \& Economics 21.1:69-80. http://dx.doi.org/10.1080/0144619032000065126

Maslach, Christina and Julie Goldberg. 1999. "Prevention of burnout: New perspectives." Applied and Preventive Psychology 7.1:63-74. http://dx.doi.org/10.1016/S0962-1849(98)80022-X

Maslach, Christina and Susan E. Jackson. 1984. "Burnout in organizational settings." Applied Social Psychology Annual 5:133-153.

Maslach, Christina, Michael P. Leiter and Susan E. Jackson. 2012. "Making a Significant Difference with Burnout Interventions: Researcher and Practitioner Collaboration." Journal of Organizational Behavior 33:296-300. http://dx.doi.org/10.1002/job.784

Maslach, Christina, Wilmar B. Schaufeli and Michael P. Leiter. 2001. "Job Burnout." Annual Review of Psychology 52:397-422. http://dx.doi.org/10.1146/annurev.psych.52.1.397

Maslach, Christina. 1993. "Burnout: A multidimensional perspective." Pp. 19-32 in Professional Burnout: recent developments in theory and research, edited by W.B. Schaufeli, C. Maslach, and T. Marek. Philadelphia, PA, US: Taylor \& Francis.

Maslach, Christina. 2003. Burnout: The cost of caring. ISHK.

McCrae, Robert R. and Paul T. Costa. 1987. "Validation of the fivefactor model of personality across instruments and observers." Journal of Personality and Social Psychology 52.1:81-90 http://dx.doi.org/10.1037/0022-3514.52.1.81

Morgan, B. and K. de Bruin. 2010. "The Relationship between the Big Five Personality Traits and Burnout in South African University Students." South African Journal of Psychology 40(2):182-91. http://dx.doi.org/10.1177/008124631004000208

Piedmont, R. L. 1993. "A Longitudinal Analysis of Burnout in the Health Care Setting: The Role of Personal Dispositions." Journal of Personality Assessment 61(3):457-73. http://dx.doi.org/10.1207/s15327752jpa6103 3 
Pines, Ayala M. 1993. "Burnout: an Existential Perspective." (Pp 3351) in Professional Burnout: Recent Developments In Theory and Research, edited by W.B. Schaufeli, C. Maslach, and T. Marek. Philadelphia, PA, US: Taylor \& Francis.

Podsakoff, Philip M., Scott B. MacKenzie, Jeong-Yeon, Lee and Nathan P. Podsakoff. 2003. "Common Method Biases In Behavioral Research: A Critical Review Of The Literature And Recommended Remedies." Journal Of Applied Psychology, 88 (5):879-903. http://dx.doi.org/10.1037/0021-9010.88.5.879

Rostami, Zeinab and Mohammad Reza Abedi. 2012. "Does academic burnout predict life satisfaction or life satisfaction is predictor of academic burnout?." Interdisciplinary Journal of Contemporary Research in Business 3.12:877-895.

Santinello, Massimo, Gianmarco Altoè, and Chiara Verzelletti. 2006. "Sviluppo E Validazione Del Link Burnout Questionnaire." Risorsa Uomo 12(4):385-396.

Schaufeli, Wilmar and Dirk Enzmann. 1998. The burnout companion to study and practice: A critical analysis. Philadelphia, PA, US: Taylor \& Francis.

Schaufeli, Wilmar B. 2003. "Past performance and future perspectives of burnout research." South African Journal of Industrial Psychology 29.4:1-15. http://dx.doi.org/10.4102/sajip.v29i4.127

Schaufeli, Wilmar B., Michael P. Leiter and Christina Maslach. 2009. "Burnout: 35 Years of Research and Practice." Career Development International 14(3):204-20. http://dx.doi.org/10.1108/13620430910966406

Singh, Jagdip, Jerry R. Goolsby and Gary K. Rhoads. 1994. "Behavioral and psychological consequences of boundary spanning burnout for customer service representatives." Journal of Marketing Research 31:558-569. http://dx.doi.org/10.2307/3151883

Smith, Timothy W. and Paula G. Williams. 1992. "Personality and Health: Advantages and Limitations of the Five-Factor Model." Journal of Personality 60.2:395-425. http://dx.doi.org/10.1111/j.1467-6494.1992.tb00978.x

Sonnenschein, Mieke, Marjolijn J. Sorbi, Lorenz J.P. van Doornen, Wilmar B. Schaufeli and Cora J. M. Maas. 2007. "Evidence That Impaired Sleep Recovery May Complicate Burnout
Improvement Independently of Depressive Mood." Journal of Psychosomatic Research 62(4):487-94

http://dx.doi.org/10.1016/j.jpsychores.2006.11.011

Suls, Jerry and René Martin. 2005. "The Daily Life of the GardenVariety Neurotic: Reactivity, Stressor Exposure, Mood Spillover, and Maladaptive Coping." Journal of Personality 73.6: $1485-1510$

http://dx.doi.org/10.1111/j.1467-6494.2005.00356.x

Thoresen, Carl J., Seth A. Kaplan, Adam P. Barsky, Christopher R. Warren, Kelly de Chermont. 2003. "The Affective Underpinnings of Job Perceptions and Attitudes: a MetaAnalytic Review and Integration." Psychological Bulletin 129:914-945. http://dx.doi.org/10.1037/0033-2909.129.6.914

Vollrath, Margarete. 2001. "Personality and stress." Scandinavian Journal of Psychology 42.4: 335-347. http://dx.doi.org/10.1111/1467-9450.00245

Watson, David and Brock Hubbard. 1996. "Adaptational Style and Dispositional Structure: Coping in the Context of the Five-Factor Model." Journal of Personality 64.4:737-774. http://dx.doi.org/10.1111/j.1467-6494.1996.tb00943.x

Watson, David, James P. David and Jerry Suls. 1999. (Pp. 119-140) "Personality, Affectivity, and Coping." Coping: The Psychology of What Works (Ed. C. R. Snyder): Oxford University Press, Oxford.

Weiss, Howard M. 1996. Affective Events Theory: A Theoretical Discussion Of The Structure, Causes And Consequences Of Affective Experiences And Job Beliefs On Job Satisfaction And Variations In Affective Experiences Over Time. Research In Organizational Behavior 18:1-74.

Zellars, Kelly L., Pamela L. Perrewe and Wayne A. Hochwarter. 2000. "Burnout in Health Care: The Role of the Five Factors of Personality." Journal of Applied Social Psychology 30(8):1570-98. http://dx.doi.org/10.1111/j.1559-1816.2000.tb02456.x

Zellars, Kelly L., Wayne A. Hochwarter, Pamela L. Perrewe, Nicole Hoffman and Eric W. Ford. 2004. "Experiencing Job Burnout: The Roles of Positive and Negative Traits and States." Journal of Applied Social Psychology 34(5):887-911. http://dx.doi.org/10.1111/j.1559-1816.2004.tb02576.x

(c) 2015 Magnano et al.; Licensee Lifescience Global.

This is an open access article licensed under the terms of the Creative Commons Attribution Non-Commercial License (http://creativecommons.org/licenses/by-nc/3.0/) which permits unrestricted, non-commercial use, distribution and reproduction in any medium, provided the work is properly cited 